UDC 379.85:796.5

LBC 65.049

\title{
THE DEVELOPMENT OF NEW TYPES OF WINTER SPORTS IN THE LOWER VOLGA REGION
}

\author{
Nadezhda Aleksandrovna Kursakova \\ School № 17, Volzhskiy, Volgograd region, Russian Federation
}

\begin{abstract}
At constantly increasing attention to natural resources from the point of view of their use in the recreational purposes, the region faces a problem of lack of an attractive, competitive tourist product and the small number of the actions capable to become «growth points» of event tourism. Modern tourist and recreational development of reservoirs of the Lower Volga is based mainly on use of biological resources of territories and water areas and is carried out during the warm period of year. On the example of experience of the Netherlands and Sweden the prospect of development in the region of new winter rest is considered - Wild Ice Skating (Outdoor Skating). The sport is traditionally popular in many countries with cold winters. Provides information about the distribution of the activity abroad and in Russia. Analyses of natural conditions for development in the Lower Volga region. Proposes specific measures for the development Wild Ice Skating in the Lower Volga region. Stimulus for the development of a new sport can be a bright event - an Outdoor Ice Marathon. Developed routes designed for different levels of training and age of participants. Route length of $4 \mathrm{~km}$ for beginners and children, to 51 and $102 \mathrm{~km}$ for the experienced participants. With proper organization of the event can not only reach the level of selfsufficiency, but also to become profitable. The consequence for ice marathons in the Volga-Akhtuba floodplain is the diversification of the tourist product of the Volgograd region, increasing tourist flow, download of the tourist camps in the winter time the infrastructure of the sport, increase physical activity of the population.

Key words: development of tourism, winter activities, ice marathon, the Volga-Akhtuba floodplain, the increase of tourist flow.
\end{abstract}

УДК 379.85:796.5

ББК 65.049

\section{РАЗВИТИЕ НОВЫХ ВИДОВ АКТИВНОГО ЗИМНЕГО ОТДЫХА В НИЖНЕМ ПОВОЛЖЬЕ}

\author{
Надежда Александровна Курсакова \\ Средняя школа № 17, г. Волжский, Волгоградская область, Российская Федерация
}

\begin{abstract}
Аннотация. При постоянно возрастающем внимании к природным ресурсам с точки зрения использования их в рекреационных целях, регион сталкивается с проблемой отсутствия привлекательного, конкурентоспособного туристского продукта и малым количеством мероприятий, способных стать «точками роста» событийного туризма. Современное туристско-рекреационное освоение водоемов Нижней Волги основывается преимущественно на использовании биологических ресурсов территорий и акваторий и осуществляется в теплый период года. На примере опыта Нидерландов и Швеции рассматривается перспектива развития в регионе нового зимнего отдыха - катания на коньках по природному льду. Этот вид спорта традиционно популярен во многих странах с холодной зимой. Приводятся данные о распространении этого вида досуга за рубежом и в России. Анализируются природные условия для развития в Нижнем Поволжье. Предлагаются конкретные мероприятия для развития WildIceSkating'а в Нижнем Поволжье. Стимулом развития нового спортивного направления может стать яркое событийное мероприятие - Открытый ледовый марафон. Разработанные маршруты рассчитаны на разный уровень подготовки и возраст участников. Протяженность маршрутов от 4 км - для детей и начинающих, до 51 и 102 км - для опытных участников. (2) 1 При правильной организации мероприятие может не только выйти на уровень самоокупаемости, но и стать
\end{abstract}


прибыльным. Следствием проведения ледовых марафонов в Волго-Ахтубинской пойме будет диверсификация туристического продукта Волгоградской области, увеличение туристского потока, загрузка туристических баз в зимнее время, оформление инфраструктуры для этого вида спорта, увеличение двигательной активности населения.

Ключевые слова: развитие сферы туризма, зимний досуг, ледовый марафон, Волго-Ахтубинская пойма, увеличение туристического потока.

В последние годы неуклонно возрастает внимание к природным ресурсам с точки зрения использования их в рекреационных целях. В настоящее время туризм можно расценивать как мощную мировую индустрию [1]. Учитывая то, что потребность в отдыхе является обязательной составляющей нормального психолого-физиологического состояния человека, а развитие туризма оказывает стимулирующее воздействие на многие отрасли экономики (транспорт, связь, торговлю, строительство и др.), российские регионы, в том числе и Нижнее Поволжье, возлагают определённые надежды на развитие туризма для улучшения экономической ситуации.

Стоит отметить, что рекреационная деятельность относится к одним из наиболее экологичных видов природопользования. Создаются новые охраняемые природные территории (национальные и природные парки, памятники природы, рекреационные зоны с разнообразным статусом), выступающие в качестве комплексных туристических объектов; развитие рекреационного природопользования способствует экологическому просвещению туристов и местных жителей, путём их вовлечения в сферу туристического обслуживания [3]. Рекреационное природопользование позволяет использовать природные ресурсы с минимальным отрицательным воздействием на ландшафт (созерцание экскурсионных объектов, пейзажей, фототуризм). Помимо этого, развитие рекреационного природопользования способствует экологическому просвещению туристов и местных жителей путём вовлечения их в сферу туристического обслуживания.

Именно благодаря рекреации появляется мощный стимул поддержания благоприятной экологической обстановки на территории, сохранения своеобразия природных ландшафтов в неизмененном состоянии и их реставрации $[8,14]$, так как именно это является ос- новными требованиями рекреационной деятельности.

Учитывая все вышеперечисленное, можно прогнозировать дальнейшее развитие сферы туризма. Между тем регион сталкивается с такими проблемами, как отсутствие привлекательного, конкурентоспособного туристского продукта и малым количеством мероприятий, способных стать «точками роста» событийного туризма [5].

Надо отметить, что на территории Нижней Волги значительную роль в организации отдыха населения играют водные объекты, которые значительно повышают рекреационную ценность ландшафтов. Но современное туристско-рекреационное освоение водоемов Нижней Волги основывается преимущественно на использовании биологических ресурсов территорий и акваторий. Ландшафтно-экологические условия поймы, дельты и западных подстепных ильменей предоставляют возможности для развития таких видов рекреации, как охота и рыбалка. Гидрографическая сеть Нижней Волги имеет важное транспортное значение, в том числе используется для развития туристских и экскурсионно-прогулочных перевозок. Специфичность и экзотичность ландшафтов являются предпосылкой развития таких видов рекреационных занятий, как научный (орнитологический, познавательный, исторический), экстремальный и другие виды туризма. Эти виды относятся к перспективным и уже пользуются спросом у рекреантов $[4,11]$.

Между тем, Волга - брэнд, которому необходимо более активное продвижение. Это, безусловно, один из символов России. Главная река страны, родина русского этноса, перекресток цивилизаций... «Ниша» этого бренда должна быть заполнена до предела на всех уровнях. Летом это круизы на теплоходах, культурный, исторический, рыболовный и экологический туризм. Что же можно предложить туристам в зимний период? 
Катание на коньках популярно во многих странах с холодной зимой [23]. В России это вполне обычный вид зимнего досуга, для определения которого наиболее подходящим нам кажется бытующий за рубежом термин «Wild Ice Sкating» или «Outdoor skating» - катание на коньках по дикому (природному) льду (катание за пределами помещений) [26]. Коньки прекрасно развивают сердечно-сосудистую, дыхательную системы и общую координацию движений [25], кроме того, отличаются небольшим травматизмом, по сравнению с другими популярными видами спорта [17]. Wild Ice Skating постепенно набирает популярность в мире. Так, знаменитый шведский марафон Vikingarännet (The Viking Run - Гонка Викингов) - 80-ти километровый забег на коньках из города Уппсала в Стокгольм. Каждый год это мероприятие привлекает десятки тысяч любителей активного отдыха и коньков. Пошведски это развлечение называется Långfärdsskidskor - катание по льду на большие дистанции [15]. В течение всей зимы практикуется катание по морским заливам и проливам в районе Стокгольма. Здесь работают инструкторы для начинающих, имеется много пунктов проката инвентаря, туроператоры даже предлагают пакетные WildIceSkating-туры.

Огромной популярностью пользуется это увлечение в Нидерландах - на родине коньков. Здесь организация ледовых марафонов лимитирована климатическими условиями, поэтому проводить их удается не ежегодно [22]. Событие это называется Elfstedentocht (дословно - Тур одиннадцати городов) и представляет собой забег на коньках по льду каналов провинции Фрисланд. Общая протяженность маршрута составляет почти 200 км. Принять участие в туре может не каждый. 200 профессиональных конькобежцев и 16000 любителей соревнуются на дистанции в две сотни километров. Большего количества участников лед просто не может выдержать. Но желающих принять участие в Туре гораздо больше. Поэтому для того, чтобы быть допущенным к забегу, нужно состоять в специальном клубе. Количество членов клуба строго фиксировано и составляет около 20000 человек. При этом около двух тысяч человек уже несколько лет стоят в «листе ожидания», чтобы попасть в клуб [12].
Увлечение набирает популярность в Канаде и США. Например, в Оттаве действует знаменитый марафон International Big Rideau Lake Speed Skating Marathon [6]. Катание по Каналу Рюдо - популярнейший вид зимнего досуга $[24,27]$.

Возникает парадоксальная ситуация - из России, где зимой льда более чем достаточно, наши граждане России отправляются кататься на коньках в Скандинавию. Между тем, зарубежные исследователи отмечают, что в связи с глобальным потеплением продолжительность зимы в Европе и Северной Америке сокращается, и условия для занятий зимними видами спорта ухудшаются [18-21].

Причин этому несколько:

1. «Нераскрученность» этого вида зимнего досуга. Не хватает медийной поддержки, нет сложившегося образа Wild Ice Skating'а в нашей стране. Очень показателен пример растущей быстрыми темпами популярности горнолыжного спорта. За последние несколько лет горные лыжи и сноуборд стали чрезвычайно популярны, посещаемость кавказских горнолыжных курортов устойчиво растет, во всех регионах, включая Волгоградскую область, открываются небольшие горнолыжные станции. Это происходит, несмотря на высокую себестоимость горнолыжного спорта, которая складывается из значительной стоимости оборудования и специфической инфраструктуры.

2. Отсутствие организованной инфраструктуры. В регионе есть множество всесезонных турбаз, расположенных на берегах рек, идеальные природные условия - ровный лед, относительно теплая зимняя погода, привлекательные зимние ландшафты Волго-Ахтубинской поймы. Есть катки с прокатом инвентаря (коньков). Необходимо объединить это в единую систему, дополнить квалифицированными инструкторами, которые помогут новичкам сделать первые шаги.

3. Для продвижения этого досуга необходимы яркие событийные мероприятия, называемые в туриндустрии «Event»- фестивали, марафоны, ярмарки. Это мощный толчок к популяризации, так как мероприятия подобного рода привлекают туристов из других регионов, широко освещаются в прессе, охватывают широкий круг местных жителей - как участников, так и зрителей. 
Единственным российским примером подобного рода является проводимый на Байкале в начале весны Открытый Байкальский марафон [7]. Время проведения связано с климатическими условиями - зимой на Байкале очень холодно и ветрено. Помимо этого, значимым моментом является отсутствие конкуренции с аналогичными мероприятиями в Европейской части России.

Для проведения массовых мероприятий на природном льду подходят водоемы с относительно малоподвижной водой. Крупные и средние реки в Нижнем Поволжье замерзают значительно позже стоячих водоемов, ледовый покров на них имеет непостоянную мощность и представляет опасность для спортсменов-конькобежцев. В течении декабря 2016 - января 2017 года нами были обследованы 2 перспективных для организации ледовых марафонов участка:

1. Левобережье южной части Волгоградского водохранилища. За время существования водохранилища в результате абразионных процессов здесь выработана отмель шириной 200-300 метров с глубинами до 3 метров [13]. При отсутствии здесь стоковых течений ледовый покров необходимой мощности (1015 см) формируется здесь раньше, чем на основной части акватории [2]. Однако, лед, формирующийся в условиях постоянного ветрового воздействия, имеет нежелательные для ледовых марафонов качества - бугристую поверхность, наличие обширных полей торошения. Пейзажи побережья здесь малопривлекательны, прибрежная территория занята, преимущественно, садоводческими товариществами. Полностью отсутствует туристская инфраструктура - турбазы, гостиницы.

2. Внутренние водотоки Волго-Ахтубинской поймы - ерики. Обследовано несколько крупных ериков - Старая Ахтуба, Каширин, Бугай. В условиях Волго-Ахтубинской поймы наиболее подходящим местом проведения является ерик Каширин в Среднеахтубинском районе Волгоградской области, который на разных участках имеет названия - Пахотный, Гнилой, Каширин, Булгаков. Маршруты, разработанные для проведения марафона, имеют удобную транспортную логистику. Помимо этого, по берегам ериков располагаются всесезонные туристические базы, которые могли бы предоставлять услуги по размещению, питанию, предоставлению оборудования для желающих принять участие в марафоне. Ерик сильно меандрирует, берега его покрыты лесом, что увеличивает эстетическую привлекательность маршрута марафона.

Ежегодный ледовый марафон в соответствии с климатическими особенностями территории оптимально проводить в декабре. В это время устанавливается прочный ледовый покров, а поверхность льда еще не покрыта снегом $[10,14]$. Погодные условия в это время в районе Волгограда довольно комфортные - по многолетним данным средняя температура декабря $-6,1^{\circ} \mathrm{C}$, а в дневное время обычно чуть ниже $0^{\circ} \mathrm{C}$ [9].

Необходимо отметить, что разработанные маршруты рассчитаны на разный уровень подготовки и возраст участников. Протяженность маршрутов от 4 км - для детей и начинающих, до 51 и 102 км - для опытных участников. Последние две дистанции могут быть расценены как квалификационные испытания для опытных конькобежцев, так как по степени нагрузки они сопоставимы с традиционными летними полумарафонами и марафонами.

Меняющиеся из года в год погодные условия - температура воздуха, ветер, качество льда, количество снега, будут способствовать уникальности каждого марафона. Учитывая время проведения марафона «Волжский лед», мероприятие не будет составлять конкуренцию Байкальскому марафону.

У Волгоградской области есть многолетний опыт проведения летних марафонов Эльтонский марафон пустынных степей «Elton Ultra Trail». В первых Эльтонских супермарафонах участвовало по 1-3 человека, в мае 2017 года он проводился уже в 5-й раз и собрал более 300 участников со всей России, ближнего и дальнего зарубежья. Таким образом, за несколько лет марафон превратился в успешное коммерческое предприятие - регистрационный сбор участника составляет от 4 до 8 тыс. рублей в зависимости от дистанции [16]. Сформировался круг спонсоров. Пример этого марафона очень показателен - это лишь один из серии марафонов, организуемых в разных регионах России и мира в различных ландшафтных и климатических условиях. 
Учитывая то, что первый марафон - тестовое мероприятие, его основная задача состоит в отработке взаимодействия организаторов, участников забега, волонтеров, административных структур. Организация первого ледового марафона не требует дополнительного финансирования.

Крайне важно продвижение марафона в средствах массовой информации и социальных сетях.

При правильной организации после проведения тестирования можно организовать ледовый марафон как полноценное туристическое мероприятие - с привлечением спонсоров, широкой рекламой, взиманием организационного сбора с участников. В этом случае мероприятие может не только выйти на уровень самоокупаемости, но и стать прибыльным.

Следствием проведения ледовых марафонов в Волго-Ахтубинской пойме будет диверсификация туристического продукта Волгоградской области, увеличение туристского потока, загрузка туристических баз в зимнее время, оформление инфраструктуры для этого вида спорта.

\section{СПИСОК ЛИТЕРАТУРЫ}

1. Биржаков, М. Б. Введение в туризм / М. Б. Биржаков. - СПб. : Издательский дом «Герда», 2001. $-320 \mathrm{c}$.

2. Гидрометеорологический режим озер и водохранилищ СССР. Волгоградское водохранилище. - Л. : Гидрометеоиздат, 1976. - 84 с.

3. Дроздов, А.В. Как развивать туризм в национальных парках России. Рекомендации по выявлению, оценке и продвижению на рынок туристских ресурсов и туристского продукта национальных парков. Монография / А. В. Дроздов. - М. : Экоцентр «Заповедники», 2000. - 39 с.

4. Канищев, С. Н. Рекреационное природопользование на Нижней Волге: региональные проблемы и международный опыт / С. Н. Канищев, Н. А. Курсакова // Туризм и рекреация: инновации и ГИС-технологии : мат-лы IV Междунар. науч.практ. конф. (г. Астрахань, 13-14 мая 2011 г.). - Астрахань : Издатель : Сорокин Роман Васильевич, 2011. - C. 90-96.

5. Курсакова, Н. А. Природно-рекреационный потенциал Волгоградского Заволжья как предпосылка развития туристической деятельности / Н. А. Курсакова // Геология, география и глобальная энергия. - 2013. - № 4 (51). - С. 168-175.
6. Ледовый марафон Озера Рюдо (Канада). Available at: http://nordicstrider.com/nordicskating/ice/ index.html.

7. Открытый Байкальский ледовый марафон. - Available at: http://baikalmarathon.blogspot.ru /2016/12/2017.html.

8. Розенберг, Г. С. Волжский бассейн: на пути к устойчивому развитию / Г. С. Розенберг. Тольятти : ИЭВБ РАН ; Кассандра, 2009. - 376 с.

9. Сажин, А. Н. Погода и климат Волгоградской области / А. Н. Сажин, К. Н. Кулик, Ю. И. Васильев. - Волгоград : ФНЦ агроэкологии РАН, 2017. $334 \mathrm{c}$.

10. Солодовников, Д. А. Опыт восстановления гидрологического режима и реставрации ландшафтов на пойменных участках, выведенных из затопления / Д. А. Солодовников, С. Н. Канищев, Д. В. Золотарев, О. В. Филиппов, Н. А. Курсакова // Региональный отклик окружающей среды на глобальные изменения в Северо-Восточной и Центральной Азии : мат-лы Междунар. науч. конф. - Иркутск: Институт географии имени В. Б. Сочавы СО РАН, 2012. - T. 2. - C. 145-147.

11. Солодовников, Д. А. Рекреационное природопользование на территории Волго-Ахтубинской поймы и дельты Волги: методические рекомендации по нормированию рекреационных нагрузок и оценке состояния природных комплексов / Д. А. Солодовников, С. Н. Канищев, Д. В. Золотарев, Н. А. Курсакова. - Волгоград : ООО «Царицынская полиграфическая компания», 2012. -120 c.

12. Тур Одиннадцати Городов (Нидерланды). - Available at: https://ru.wikipedia.org/wiki/ Elfstedentocht.

13. Филиппов, О. В. Пятидесятилетние итоги развития берегов Волгоградского водохранилища / О. В. Филиппов, Д. А. Солодовников // Стрежень: Научный ежегодник. - 2010. - № 8. - С. 135-139.

14. Филиппов, О. В. Опыт восстановления деградированных ландшафтов и водных объектов Волго-Ахтубинской поймы: гидрологический аспект / О. В. Филиппов, Д. А. Солодовников, Д. В. Золотарев, С. Н. Канищев // Вестник Волгогр. гос. ун-та. Сер. 11. Естественные науки. - 2012.№ 2(4). - С. 34-43.

15. Шведский марафон The Viking Run. Available at: http://vikingarannet.com/.

16. Эльтонский марафон пустынных степей. Available at: http://elton-ultra-trail.com/main.html.

17. Aman M., Forssblad M., Henriksson-Larsŭn K. Incidence and severity of reported acute sports injuries in 35 sports using insurance registry data // Scandinavian Journal of Medicine and Science in Sports, 2016, 26 (4), pp. 451-462.

18. Bigano A., Goria A., Hamilton J., Tol R. S. J. The effect of climate change and extreme weather 
events on tourism // The Economics Of Tourism And Sustainable Development, 2005, pp. 173-196.

19. Damm A., Greuell W., Landgren O., Prettenthaler F. Impacts of $+2{ }^{\circ} \mathrm{C}$ global warming on winter tourism demand in Europe // Climate Services, 2017, 7, pp. 31-46.

20. Damyanov N.N., Matthews D.H., Mysak L.A. Observed decreases in the Canadian outdoor skating season due to recent winter warming // Environmental Research Letters, 2012, 7(1), pp. 45-53.

21. Falk M. A dynamic panel data analysis of snow depth and winter tourism // Tourism Management, 2010,31 (6), pp. 912-924.

22. Flynn K., Keane K. Blades of glory: Ice skating rinks in historic settings // Preservation, 2017, 69(1), c. 52.

23. Gaudette M., Roult R., Lefebvre S. Winter Olympic Games, cities, and tourism: a systematic literature review in this domain // Journal of Sport and Tourism, 2017, 21(4), pp. 287-313.

24. Gillis N.C., Rapp T., Hasler C.T., Wachelka H., Cooke S.J. Spatial ecology of adult muskellunge (Esox masquinongy) in the urban Ottawa reach of the historic Rideau Canal, Canada // Aquatic Living Resources, 2010, 23(2), c. 225-230.

25. Mavor M.P., Hay D.C., Graham R.B. The effects of weighted skates on ice-skating kinematics, kinetics and muscular activity // Journal of Sports Sciences, 2017, 11, pp. 1-7.

26. Leese P. A more varied and exciting outdoor sports scene // Apparel International, 1998, 29(1), pp. 26-27.

27. Robertson C., McLeman R., Lawrence H. Winters too warm to skate? Citizen-science reported variability in availability of outdoor skating in Canada // Canadian Geographer, 2015, 59(4), pp. 383-390.

\section{REFERENCES}

1. Birzhakov M.B. Vvedenie v turizm [Introduction to tourism]. SPb: Gerda Publ., 2001.320 p.

2. Gidrometeorologicheskij rezhim ozer $\mathrm{i}$ vodohranilishh SSSR. Volgogradskoe vodohranilishhe. [Hydrometeorological regime of lakes and reservoirs of the USSR. Volgograd reservoir.]. L.: Gidrometeoizdat, $1976.84 \mathrm{p}$.

3. Drozdov A.V. Kak razvivat' turizm v nacional'nyh parkah Rossii. Rekomendacii po vyjavleniju, ocenke i prodvizheniju na rynok turistskih resursov i turistskogo produkta nacional'nyh parkov [How to develop tourism in national parks of Russia. Recommendations about identification, assessment and advance on the market of tourist resources and a tourist product of national parks]. Moscow, Jekocentr «Zapovedniki», 2000. -39 p.
4. Kanishchev S.N., Kursakova N.A. Rekreacionnoe prirodopol'zovanie na Nizhnej Volge: regional'nye problemy i mezhdunarodnyj opyt [Recreational environmental management on the Lower Volga: regional problems and international experience]. Turizm i rekreacija: innovacii i GIS-tehnologii: materialy IV mezhdunarodnoj nauchno-prakticheskoj konferencii [Tourism and recreation: innovations and GIStechnologies: materials IV of the international scientific and practical conference (Astrakhan, on May 13-14, 2011)] - Astrakhan: Publisher: Sorokin Roman Vasilyevich, 2011. Pp. 90-96.

5. Kursakova N.A. Prirodno-rekreacionnyj potencial Volgogradskogo Zavolzh'ja kak predposylka razvitija turisticheskoj dejatel'nosti [Naturalrecreational potential of the Volgograd Trans-Volga region as a prerequisite of tourism development]. Geologija, geografija i global'naja jenergija [Geology, geography and global energy]. 2013. No. 4 (51). Pp. 168-175.

6. International Big Rideau Lake Speed Skating Marathon. Available at: http://nordicstrider.com/ nordicskating/ice/index.html.

7. Otkrytyj Bajkal'skij ledovyj marafon [Outdoor Baikal ice marathon]. Available at: http:// baikalmarathon.blogspot.ru/2016/12/2017.html.

8. Rosenberg G.S. Volzhskij bassejn: na puti k ustojchivomu razvitiju [Volga basin: on the way to sustainable development]. Togliatti: IEVB RAS; Cassandra, 2009. Pp. 283-291.

9. Sazhin A.N., Kulik K.N., Vasil'ev Ju.I. Pogoda i klimat Volgogradskoj oblasti [Weather and climate of the Volgograd region]. Volgograd: FNC agrojekologii RAN, 2017.334 p.

10. Solodovnikov D.A., Kanishchev S.N., Zolotarev D.V., Filippov O.V., Kursakova N.A. Opyt vosstanovlenija gidrologicheskogo rezhima i restavracii landshaftov na pojmennyh uchastkah, vyvedennyh iz zatoplenija [Experience of restoration of the hydrological mode and restoration of landscapes on the inundated sites brought out of flooding]. Regional'nyj otklik okruzhajushhej sredy na global'nye izmenenija v Severo-Vostochnoj i Central'noj Azii: Materialy Mezhdunarodnoj nauchnoj konferencii. [The Regional response of the environment to global changes in Northeast and Central Asia: Materials of the International scientific conference]. Russian Academy of Sciences, Siberian office, Institute of geography of V.B. Sochava, Russian Geographical Society, East Siberian office. 2012. Pp. 145-147.

11. Solodovnikov D.A., Kanishchev S.N., Zolotarev D.V., Kursakova N.A. Rekreacionnoe prirodopol'zovanie na territorii Volgo-Ahtubinskoj pojmy i del'ty Volgi: metodicheskie rekomendacii po normirovaniju rekreacionnyh nagruzok i ocenke sostojanija prirodnyh kompleksov [Recreational 
environmental management in the territory of the VolgaAkhtubinsk flood plain and the delta of Volga: method. recommendations about rationing of recreational loadings and assessment of a condition of natural complexes] Volgograd: Tsaritsyn Printing Company, 2012. - 120 p.

12. Tur Odinnadcati Gorodov (Niderlandy) [The Eleven Cities Tour (Netherlands)]. Available at: https:/ /ru.wikipedia.org/wiki/Elfstedentocht

13. Filippov O.V., Solodovnikov D.A. Pjatidesjatiletnie itogi razvitija beregov Volgogradskogo vodohranilishha [Fifty-years the results of the development of banks of the Volgograd reservoir]. Strezhen': Nauchnyj ezhegodnik [Strezhen: Scientific Yearbook]. 2010. No. 8. Pp. 135-139.

14. Filippov O.V., Solodovnikov D.A., Zolotarev D.V., Kanishchev S.N. Opyt vosstanovlenija degradirovannyh landshaftov i vodnyh ob\#ektov VolgoAhtubinskoj pojmy: gidrologicheskij aspekt [Experience of restoration degradirovannykh of landscapes and water objects of the Volga-Akhtuba flood plain: hydrological aspect]. Vestnik Volgogradskogo gosudarstvennogo universiteta. Ser. 11, Estestvennye nauki. [Messenger Volgogr. state. University. Vol. 11. Natural sciences]. 2012. No. 2 (4). Pp. 34-43.

15. The Viking Run marathon. Available at: http:// vikingarannet.com/.

16. Jel'tonskij marafon pustynnyh stepej [Elton marathon across the desert steppes]. Available at: http://elton-ultra-trail.com/main.html.

17. Eman, M., Forssblad, M., HenrikssonLarsŭn, K. Incidence and severity of reported acute sports injuries in 35 sports using insurance registry data // Scandinavian Journal of Medicine and Science in Sports, 2016, 26(4), pp. 451-462.

18. Bigano, A., Goria, A., Hamilton, J., Tol, R.S.J. The effect of climate change and extreme weather events on tourism // The Economics Of Tourism And Sustainable Development, 2005, pp. 173-196.

19. Damm, A., Greuell, W., Landgren, O., Prettenthaler, F. Impacts of $+2{ }^{\circ} \mathrm{C}$ global warming on winter tourism demand in Europe // Climate Services, 2017, 7, pp. 31-46.

20. Damyanov, N.N., Damon Matthews, H., Mysak, L.A. Observed decreases in the Canadian outdoor skating season due to recent winter warming // Environmental Research Letters, 2012, 7(1), pp. 45-53.

21. Falk, M. A dynamic panel data analysis of snow depth and winter tourism // Tourism Management, 2010, 31 (6), pp. 912-924.

22. Flynn, K., Keane, K. Blades of glory: Ice skating rinks in historic settings // Preservation, 2017, 69(1), c. 52.

23. Gaudette, M., Roult, R., Lefebvre, S. Winter Olympic Games, cities, and tourism: a systematic literature review in this domain // Journal of Sport and Tourism, 2017, 21(4), pp. 287-313.

24. Gillis, N.C., Rapp, T., Hasler, C.T., Wachelka, H., Cooke, S.J. Spatial ecology of adult muskellunge (Esox masquinongy) in the urban Ottawa reach of the historic Rideau Canal, Canada // Aquatic Living Resources, 2010, 23(2), c. 225-230.

25. Mavor, M.P., Hay, D.C., Graham, R.B. The effects of weighted skates on ice-skating kinematics, kinetics and muscular activity // Journal of Sports Sciences, 2017, 11, pp. 1-7.

26. Leese, P. A more varied and exciting outdoor sports scene // Apparel International, 1998, 29(1), pp. 26-27.

27. Robertson, C., McLeman, R., Lawrence, H. Winters too warm to skate? Citizen-science reported variability in availability of outdoor skating in Canada // Canadian Geographer, 2015, 59(4), pp. 383-390.

\section{Information about the Author}

Nadezhda Aleksandrovna Kursakova, Teacher of Geography, Municipal Educational Institution “School № 17”, Clara Nechaeva St., 10, 4044131 Volzhskiy, Volgograd region, Russian Federation, nadya-kursakova@yandex.ru.

\section{Информация об авторе}

Надежда Александровна Курсакова, учитель географии, Муниципальное образовательное учреждение «Средняя школа № 17», ул. Клары Нечаевой, 10, 4044131 г. Волжский, Волгоградская область, Российская Федерация, nadya-kursakova@yandex.ru. 